\title{
FIELD OF DREAMS OR DREAM TEAM? Assessing Two Models for Drought Impact Reporting in the Semiarid Southwest
}

\author{
by Alison M. Meadow, Michael A. Crimmins, and Daniel B. Ferguson
}

\author{
Overcommitment and time constraints hinder the effectiveness of volunteers \\ reporting drought impacts, whereas agency personnel can provide useable, \\ consistent reports on a long-term basis.
}

I

$\mathrm{n}$ the 1989 film Field of Dreams, the main character, Ray Kinsella, is assured by a ghostly presence that, if he builds a baseball diamond in his cornfield, "people will come," thus saving him from financial and personal ruin. Drought impacts reporting in the United States is currently based on a Field of Dreams model that assumes that, if websites and portals are built, people will freely contribute their impact observations to bolster hydroclimatic data, thus generating information on which to base decisions about drought conditions. In the movie, of course, the baseball field does attract both players and spectators, thus saving the farm and family. The question for the climate science and drought response communities, however,

AfFiliations: Meadow ANd Ferguson-Institute of the Environment, University of Arizona, Tucson, Arizona; CRIMmINSDepartment of Soil, Water, and Environmental Science, University of Arizona, Tucson, Arizona CORRESPONDING AUTHOR: Alison M. Meadow, 715 N. Park Ave, Second Floor, P.O. Box 210156, Tucson, AZ 85719 E-mail: meadow@email.arizona.edu

The abstract for this article can be found in this issue, following the table of contents.

DOI:10.1175/BAMS-D-II-00168.I

A supplement to this article is available online (10.1175/BAMS-D-II-00168.2)

In final form 7 January 2013

(C)2013 American Meteorological Society arises: are voluntary reporting portals effective for compiling critical information necessary to track the complex, multisectoral aspects of drought and to support policy responses and planning efforts?

In contrast to the Field of Dreams model, when the International Olympic Committee first allowed professional athletes to compete in the Olympic Games beginning in 1992, the United States assembled a basketball team made up of, arguably, the 12 best players in the world at the time. Opposing teams lost by an average of 44 points per game and the U.S. "Dream Team" took home the gold medal. They not only produced results for their team and their country, but they engaged whole new audiences, thereby broadening basketball's impact across the world. Would drought impacts reporting efforts be improved if-at least as a preliminary step-they were focused on compiling information from trained professionals, intimately familiar with their regions, who can commit to consistent reporting? The results from a case study of one drought impacts reporting system point toward this conclusion.

\section{OVERVIEW OF ARIZONA DROUGHT-} WATCH. Arizona DroughtWatch (AZDW) is a web-based data collection system designed to gather drought impacts reports from across the state to inform decisions about drought status and response options in Arizona (Fig. 1). AZDW grew out of a 
monitoring and reporting framework within the 2003 Arizona drought preparedness plan that uses a series of committees to coordinate the state's drought monitoring and responses.

An extensive and persistent drought has gripped much of the southwestern United States with few breaks over the past 10 years. Arizona has been especially hard hit by ongoing drought conditions that have set in motion record-setting fire seasons, declining base flows in perennial streams, declining rangeland conditions, and large-scale forest mortality. Accompanying economic impacts have emerged as well with losses close to $\$ 400$ million in the livestock industry during the peak drought year of 2002 and a reduction in tourism revenue as forest closures and low water levels limited recreational activities at times over the past decade (McKinnon 2006; Wagner 2007).

These conditions highlighted the need for local planning and responses to drought by the state of Arizona. In 2003, then Arizona governor Janet Napolitano issued Executive Order 2003-12, establishing the Governor's Drought Task Force to address drought issues in the state. The Arizona Department of Water Resources (ADWR) was tasked with providing leadership in this effort through their drought program. A drought plan was developed with the goals of identifying the impacts of drought to the various sectors, defining the sources of drought vulnerability and outlining a monitoring program, and preparing drought response options and drought mitigation strategies (Governor's Drought Task Force 2004).

Three groups were created to achieve these goals:

Local drought impact groups (LDIG): county-level ad hoc volunteer groups of local stakeholders led by Arizona Cooperative Extension and county emergency management with a mission to inform the public about drought, provide impact information, and develop and implement local mitigation and response options;

Monitoring technical committee (MTC): statewide group of experts who use qualitative drought impact observations and quantitative drought monitoring metrics (e.g., standardized precipitation index) to

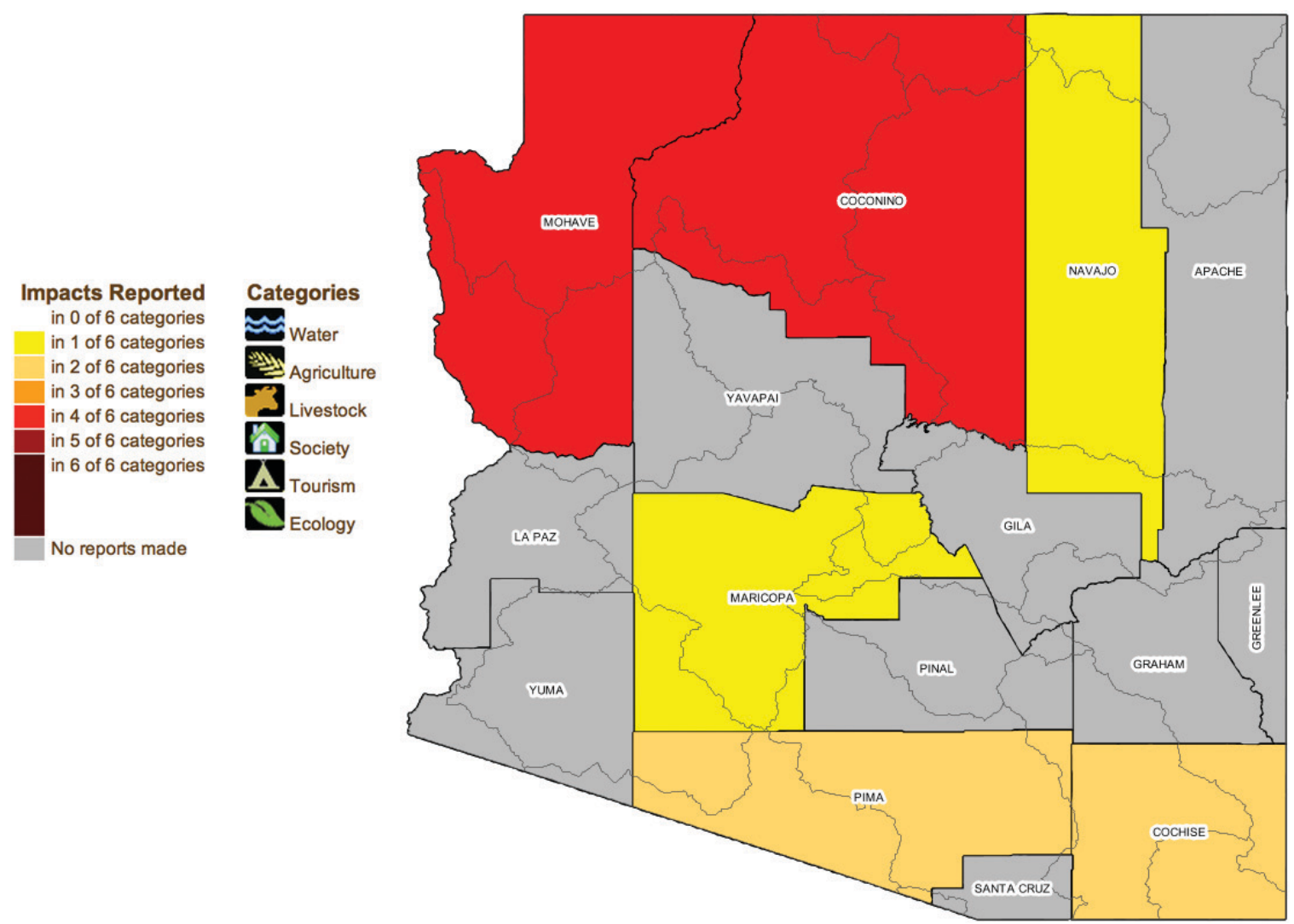

FIG. I. AZDW is designed to collect qualitative information about drought impacts in six categories: water, agriculture, livestock, society, tourism, and ecology. The summary map above shows the total number of categories in which reports were made for the study period (March 2009-August 2010) and where the reports came from. Gray areas indicate no drought impacts were reported. 
track drought conditions and develop drought status maps for the state of Arizona; and

Interagency coordinating group (ICG): an advisory board of state, federal, and nongovernmental resource management agencies and organizations that meets twice a year to evaluate drought conditions presented by the monitoring technical committee and make recommendations to the governor that ultimately supports the declaration, stay, or lifting of a state drought emergency.

Although various federal and state agencies conduct their own drought monitoring in Arizona, the drought preparedness plan assigns LDIGs this role within the official decision-making structure. LDIGs are intended to include representatives of federal and state resource management agencies, tribes, local government, and water providers, among others. The intention may have been that agency representatives would feed their drought observations through the LDIG channel, but this does not appear to be happening regularly. Instead, drought monitoring is happening in two channels: within and outside of agencies. It is not within the scope of this paper to assess the efficacy of agency monitoring or to compare the quality of agency and LDIG monitoring efforts. We focus our assessment on the system put in place via the drought plan: monitoring by the LDIGs through the vehicle of AZDW.

Implementation of the LDIGs began in 2006. As of 2012, only two counties have fully active LDIGs "due to resource constraints at the state and local level" (Arizona Department of Water Resources 2012).

Discussions with representatives from all of the existing LDIGs, beginning in 2006, on how to improve the collection and flow of drought impacts information led to the creation of the AZDW program. AZDW is a collaboration between researchers at the University of Arizona, specialists and agents with Arizona Cooperative Extension, and drought planners at the Arizona Department of Water Resources. The web-based data collection and reporting system is centered on a drought impact survey customized to sectors and natural resources specific to Arizona. The program is designed to collect an updated survey from each observer each month in order to track changes over time in drought impacts for a location(s) specified by the observer. An important element of the survey is the option for reporters to submit qualitative information on the trend of the impact (i.e., improving, status quo, and deteriorating). Related to trend observations is the expectation that observers also submit "all clear" reports once a drought impact has abated in the judgment of the observer. The site was officially launched in March 2009 in "beta" form to engage users in operational use and testing. Since launch, the site has been continually refined based on feedback from users.

Despite extensive collaboration with LDIG members during the development of AZDW, few of these target program participants are filing impact reports with any regularity and few members of the public have joined the ranks of impact reporters. In late 2009, AZDW developers embarked on a formal evaluation of the program to determine the following:

- factors that have inhibited volunteer impacts reporters' use of AZDW and

- approaches that would help more effectively bring qualitative data into the drought response decision-making process.

Our evaluation of AZDW found that the model employed by the Arizona drought preparedness plan to use volunteer LDIG members as drought impacts reporters (via AZDW) should have been effective, given that the scale of the effort and engagement process was designed to fit regional decision-making needs (Pulwarty et al. 2009); however, a lack of support for the efforts of volunteer LDIG members (and other members of the public) has hindered participation in drought impacts monitoring. With no funds allocated to the LDIGs, they remained an entirely volunteer organization made up of good-intentioned but overcommitted regional stakeholders who have been unable to provide consistent drought impacts reports in the manner necessary for sound policy decision making.

A second factor that has hindered the success of drought impacts reporting through AZDW is the very nature of drought itself. Drought can be difficult to definitively characterize for at least two reasons that have a bearing on the AZDW program. First, the time lag between precipitation deficits and impacts to social and ecological systems can be substantial, particularly in semiarid and arid regions, making it difficult for observers to confidently attribute conditions to drought. We also found intended users of AZDW were reluctant to report observations when they did not perceive drought impacts in their region. The challenge of deciding whether a specific location is in or out of drought and the complexity and uncertainty of identifying drought impacts seem to have contributed to the relatively low numbers of impact observers who were willing to report regional conditions to AZDW. 
Based on our evaluation of the development and implementation of the AZDW program, we conclude that is has been hindered by its reliance on volunteer reporters and on a system divorced from the drought monitoring already taking place within resource management agencies. We suggest that the approach most likely to succeed will involve engaging with and gaining institutional support from resource management agencies with personnel who have field monitoring expertise and who can commit these staff to providing consistent and regular drought impacts reports. Utilizing a drought impacts monitoring dream team is a critical first step in creating a functional drought impacts monitoring program with the potential for long-term stability. By building a system that has a backbone of experts, we believe the odds will be substantially increased that other drought impact observers will follow their lead and make routine contributions. Furthermore, entraining these experts in the process of interpreting impacts and linking them to quantitative drought monitoring metrics enhances and supports the difficult task of determining drought status using a complex mix of data types and sources. We essentially suggest a model that has a dream team playing on a field of dreams. After all, the reason people showed up on the field of dreams was the presence of baseball legends in the form of a ghostly dream team.

\section{ENGAGING A BROAD NETWORK OF IMPACT OBSERVERS IN DROUGHT MONITORING. The last two decades have seen} a substantial movement away from drought policies that are reactive and crisis oriented to responses that are more proactive and focused on risk management (Hayes et al. 2004; Wilhite et al. 2000). A primary objective of the risk-management stance is to recognize drought as an inherent part of a dynamic climate system and therefore plan for drought rather than be surprised and devastated by its onset. A central tenet of the risk-management approach is the need for consistent quality monitoring of environmental conditions so that decision makers are attuned to worsening conditions in real time, thus allowing them the chance to implement drought response protocols and policies to mitigate the worst impacts before they occur.

While an improvement over the crisis-response mode of dealing with drought, the risk-management approach contains an intrinsic challenge: monitoring drought is much more complex than simply measuring precipitation (Wilhite et al. 2000). As has been observed many times, drought is notoriously difficult to define much less characterize as it is happening (Redmond 2002; Western Governors Association 2004; World Meteorological Organization 2006). Since at its most fundamental level drought is simply "insufficient water to meet needs" (Redmond 2002), robust drought monitoring should be multisector and regionally specific (World Meteorological Organization 2006). The innate complexity of characterizing drought has resulted in a wide range of drought indices (Heim 2002), all derived from physical measures of drought and each with strengths and weaknesses (Keyantash and Dracup 2002). In turn, state drought policies across the United States have adopted diverse sets of drought indicators and triggers; nearly all of which are tied back to a particular drought index or set of indices (Quiring 2009; Robine 2011). When drought is monitored purely based on indices derived from climate variables or from socioeconomic data that are readily available (e.g., commodity prices), problems can arise if the true impacts of dry conditions are not captured because of insufficient data, lags in data availability, poor data quality, or data collected at the wrong scale.

One solution to these problems is to develop methods that allow qualitative drought impact reporting to become a central element of drought monitoring (Hayes et al. 2011; Western Governors Association 2004; Wilhite et al. 2007; World Meteorological Organization, 2006). There is a growing realization that it is important to devise robust approaches to collect, quantify, and aggregate drought impact reports and to develop fully functional drought early warning systems. To date, however, efforts to address this gap in drought monitoring have been sparse. Existing efforts, such as AZDW, tend to focus on input from volunteer participants to amass a range of impacts from people experiencing them in real time. As we discovered with AZDW, however, entraining volunteers in this complex task has its own set of challenges.

Public participation in environmental monitoring and decision making. Given the need to determine how drought is impacting a range of people and places, proactive drought monitoring must engage people from a broad cross section of a region: for example, people from different geographic areas and representing different economic sectors such as agriculture, tourism, or water management. AZDW relies on participation of volunteers-most of them LDIG members, but some have also been recruited (sometimes through LDIG members) from the 
general population-for its impact reports. While LDIG members tend to be professional resource managers, their participation in LDIGs and AZDW has been voluntary and unpaid. Thus, the literature on public participation in policy decisions can help to elucidate some of the issues faced by LDIG members and AZDW developers in engaging and retaining drought impacts reporters.

Although scientists and decision makers have been urged for several years to engage with the public and incorporate public knowledge and opinions into plans and policies (Dietz and Stern 2008; Lemos and Morehouse 2005), there are in fact few clear pathways to achieving effective public engagement (PytlikZillig and Tomkins 2011; Talwar et al. 2011). However, studies of past public engagement attempts give us clues to effective approaches and barriers to engaging the public in environmental decision making. Arnstein's (1969) "ladder of citizen participation" outlines a continuum of participatory practices that range from manipulation of the citizenry, in which people are used simply to rubberstamp projects, through full citizen control of the process. Arnstein demonstrated that not all public engagement processes are equal, although they may all satisfy an "engagement" requirement. As Olson (1965) stressed, people tend to require adequate and appropriate incentives to contribute to group actions or movements.

Based on the foundation laid out by Arnstein (1969) and Olson (1965), several general principles have emerged to help guide the process of engaging the public in scientific and policy decisions. Dietz and Stern (2008) recommend that government agencies attempting to engage the public in decision making do so with the following: clarity of purpose; a commitment to use the process to inform their decisions; adequate funding and staff; appropriate timing in relation to decisions; a focus on implementation; and a commitment to self-assessment and learning from experience.

However, even with a well-intentioned publicparticipation plan, scientists or government agencies may find participation weak. Several recent studies provide us with insights into public nonparticipation in environmental decision making. Diduck and Sinclair (2002) examined the barriers to public participation in an environmental assessment (EA) process that required public input. They found a range of structural and individual barriers that reduced participation rates including the following: participants' overcommitment; participants not perceiving that they have a voice in the process; lack of skills (e.g., public speaking or computer or technology literacy); and lack of funding for public participation. Lack of interest was not a key factor in lack of participation: members of the public were interested and invested in the outcome of the decision but were unable or unwilling to participate for the reasons cited above. Cheng and Mattor (2006) studied participants and nonparticipants in U.S. Forest Service collaborative planning processes and found that time constraints were a primary inhibitor of public participation in the process. They also found that people were less likely to participate when they perceived that the process would not confer shared power over decisions or that the government representatives were not fair or competent. Ensuring the critical sense of "agency" for stakeholders-an understanding of how their input will be used in the decision-making process - can be aided by providing regular, clear feedback to process participants that demonstrates how their input is being applied to the decision-making process (Newman et al. 2010).

\section{ARIZONA DROUGHTWATCH PROGRAM} EVALUATION. In the fall of 2009, we undertook a formal evaluation of the AZDW program. Our evaluation team consisted of a social scientist who was previously uninvolved with AZDW (Meadow), who carried out all of the data collection for the evaluation; a climatologist and one of the principal developers of the program (Crimmins); and a social scientist with limited involvement in AZDW development (Ferguson). A total of 14 individual interviews were conducted with 4 program developers, 9 LDIG members, and 1 resource agency representative who was involved in funding AZDW. We made efforts to interview 2 members of each LDIG, but we were only successful in reaching representatives of 5 of the 15 total LDIGs (as noted above, only 2 LDIGs are considered currently active). An online survey, sent to all AZDW users in the monthly e-mail newsletter, was used to collect information from AZDW users who were not necessarily LDIG members. There are 97 registered AZDW users; we received surveys back from 13 . Individual interviews consisted of 20-25 questions, depending on each participant's level of involvement with AZDW, and lasted between 40 and $60 \mathrm{~min}$. Both the interviews and online survey asked participants about their perception of drought conditions and drought

${ }^{1}$ Please see electronic supplement for details of the survey and interview tools used in the evaluation process. 
risk, specific involvement with the development of AZDW, current use of the tool, and suggestions for improving the tool. ${ }^{1}$

\section{FINDINGS: INCONSISTENCY AND RETENTION ISSUES IN THE FIELD OF \\ DREAMS. In many ways the AZDW developers} followed model public-participation strategies. They targeted what appeared to be the right group of stakeholders, those already engaged in drought monitoring and response (LDIG members). They met with their intended audience up to 12 times, according to interview participants, to discuss both content and design issues, and they incorporated participant feedback into the design of the AZDW tool.

Yet, despite this lengthy collaborative process, few impact observers are using the tool. Over the 18 months considered in the evaluation (March 2009-August 2010), AZDW received 8.3 reports per month, with a high of 19 in June 2010 and a low of 2 in both April and June 2009. Only 40 of the 97 registered users submitted an impact report. Out of the reports, $54 \%$ came from only four users, and 5 of the 10 LDIG members interviewed as part of the evaluation reported that they do not use AZDW at all.

Our evaluation revealed several flaws in the execution of the Arizona drought preparedness plan and, by extension, AZDW that can be useful in both redesigning AZDW and in designing future drought impacts reporting systems. Some flaws are standard barriers to public engagement outlined above. Additional barriers emerged because of the complexities of drought impact monitoring. In particular, the inscrutability of drought impacts makes observing and recording them more difficult than developers expected; observers struggled with the distinction between quantitative and qualitative data and the role of each in drought monitoring.

BARRIERS TO PARTICIPATION IN ARIZONA DROUGHTWATCH. Overusing volunteers. The time commitment (Cheng and Mattor 2006) required to produce detailed drought impacts reports-or the sense of overcommitment (Diduck and Sinclair 2002) on the part of AZDW targeted users-was one of the most common reasons given by study participants for not making regular reports to AZDW. While reporting drought impacts was not intended to be time consuming, participants perceive that it is. Several people told us "[It's] another level of obligation" or "I just don't have time. I'm overwhelmed and it just doesn't rise to the top of the list of importance."
As discussed above, both the need and methods to monitor drought impacts are not well understood or developed, even within the drought community. No standard model exists, nor is it likely to be possible to develop one monitoring model that would be useful in diverse socioecological contexts. The AZDW developers attempted to address this complexity by creating a detailed list of all possible drought impacts in Arizona. However, this detailed survey in fact has contributed to lower participation because users perceived the survey as too long, confusing, and time consuming. Of the seven people who responded to the interview question about the impacts survey used by AZDW, five expressed concerns about its length and complexity (one person had not looked at it and only one respondent said it was a "good fit"). One respondent said that his community members found the survey "a little intimidating." Another replied that his reports to other agencies took "three minutes. [While] AZDW is a 20-25 minute task-it is too much time!" Two people reported that modifying and shortening the survey had helped them to collect impacts from their constituent groups. However, this raises the question of whether a shorter, less detailed survey provides the kind of information required to accurately diagnose drought conditions (see Table 1).

Consultation fatigue also arose. One participant reported that he was already filing reports with another agency and felt that AZDW was a duplication of his effort. Another suggested that her constituents were not interested in participating because "people are tired of giving data to everyone." Some potential AZDW participants were content to leave participation to others, to use Diduck and Sinclair's (2002) framing, particularly when they were aware that the information was being collected by other agencies. "NRCS has incredible range data that should be tapped into. The [agricultural] producers just want to rely on the range cons [conservationists] and soil scientists' data," noted one person when asked why producers in her county were reluctant to contribute reports to AZDW.

Lack of transparency. Dietz and Stern (2008) note the importance of "clarity of purpose" when engaging in a public-participation process. In the case of AZDW, we found that many potential impact observers were unclear about the purpose of the tool or how the data they submit to AZDW would be used. Although the respondents tended to be clear that AZDW compiles reports about local drought conditions (about 40\% specifically mentioned this function), only about $40 \%$ specifically mentioned AZDW's role in the drought 
response process, such as providing officials with information on which to base decisions about drought declarations and aid. Several respondents could not identify any way in which AZDW information is used. It does not appear that respondents see that information entered into AZDW can be and is used by decision makers, nor does the AZDW website provide examples of how the information is used. Cheng and Mattor (2006) refer to this situation as a lack of "self-efficacy." When people feel they are having an effect-selfefficacy-they are more likely to cooperate. In a policy process, it is even more important that volunteers understand exactly how their information is used so that they trust the process and the decisions. One way to demonstrate how information is used is to send regular, lucid reports (Cooper et al. 2007) to participants. AZDW sends subscribers a monthly e-mail summarizing climate and weather data and drought conditions for the state. Several evaluation participants noted that they liked the newsletter but would like more details and more description of conditions.

Perception and immediacy of drought impacts. We identified the individual perception of drought as a potential barrier to participation in AZDW, what Diduck and Sinclair (2002) referred to as "not feeling directly affected." Whether a person perceives that drought is a problem in their area seems to affect whether they participate in an impacts reporting system. AZDW relies on consistent reporting of both good and poor conditions in the state. However, we found evidence of disengagement from reporting as soon as drought conditions appeared to improve. Therefore, AZDW ended up collecting spot reports of impacts, rather than status reports that capture a fuller picture of conditions in a given region. For example, the period of May-August 2009 was particularly dry in Arizona, with precipitation totals $50 \%$ below average. Most people we interviewed considered that period to be a severe drought (81\%). AZDW received 26 reports during that period. In contrast, after a winter with $70 \%$ higher than average precipitation, few participants (only 29\%) felt their region was still in severe drought (although most were also careful to note that one rainy season is unlikely to fully alleviate a drought). Reports to AZDW fell to 18 between December 2009 and March 2010. In addition to the number of reports falling off when conditions appeared to improve, the type of reports provides insights into participants' interest in reporting. Of all of the drought impact reports collected in AZDW, $97 \%$ were of deteriorating conditions. ${ }^{2}$ Only $1 \%$ of reports cited improving conditions, and $2 \%$ reported steady conditions or no change since the previous report. Finally, several participants directly indicated that they were not interested in providing ecological status reports but would only report perceived drought. One person explained why she does not use AZDW: "I don't see it as a way to report the lack of drought. It's in the name-DroughtWatch. If I'm not

\footnotetext{
${ }^{2}$ Reporters are given the option of assigning a trend to their reports. We assume that new reports or those with an "unknown" trend assignment are reporting on deteriorating conditions because questions on the impacts survey are phrased assuming poor conditions.
}

\begin{tabular}{|c|c|c|}
\hline Location & Date of report & Drought impact \\
\hline Lower Colorado River watershed & April 2010 & $\begin{array}{l}\text { The annuals are vigorously growing. We have the start of a good } \\
\text { spring; All water tanks are full to the max at this time. Rain was } \\
\text { perfect timing to continue plant growth, and range looks the best } \\
\text { it has in } 5 \text { years. }\end{array}$ \\
\hline Rio Bavispe watershed & April 2011 & $\begin{array}{l}\text { Many ponds that normally have water at this time are dry. Little to } \\
\text { no green forage exists in the grasses or forbs. }\end{array}$ \\
\hline Santa Cruz River watershed & April 201I & $\begin{array}{l}\text { For the first time (in the period 1984-20II) I have seen browsing } \\
\text { (probably by white-tailed deer) on Agave schottii (shindagger) and } \\
\text { Yucca schottii (Schott yucca). On agaves, leaves are eaten down to } \\
\text { about } 4 \text { inches; on yuccas, younger growth in center of plants has } \\
\text { been eaten. }\end{array}$ \\
\hline Santa Cruz River watershed & April 2011 & $\begin{array}{l}\text { Drought impact is present and severe. The flow is less than last } \\
\text { year and about half the average flow seen within drought years: } \\
\text { rising severity. }\end{array}$ \\
\hline
\end{tabular}


seeing drought impacts, I'm not going to report it." Another noted, when asked why he is not using the reporting tool, that "he hasn't seen a lot of impact in the area [he's] most familiar with."

At this point, we do not have enough long-term data to discern a direct link between precipitation rates and a drop off in AZDW reports. Without consistent reports, we are not able to say whether higher rates of precipitation did alleviate drought impacts in any particular areas of the state. The apparent link between perception of drought and engagement (or disengagement) with impacts reporting points to a challenge for designing monitoring systems intended to engage the public over the long term.

The lack of interest in reporting steady or improving conditions may also relate back to the issue of confusion about the purpose of AZDW and use of information in AZDW discussed above. If participants do not understand how AZDW information is used by decision makers to make determinations about drought status they may not see the importance of long-term status reports, as opposed to erratic reports of poor or worsening conditions.

Funding public participation. We also found evidence that a lack of funding for public participation, as warned against by both Dietz and Stern (2008) and Diduck and Sinclair (2002), was a hindrance. Perhaps, more accurately, we found that the availability of funds to support drought impacts reporting boosted participation. A contrast to the generally low rates of participation in AZDW is the example of the LDIG in Mohave County. The Mohave County LDIG was able to leverage funds for a staff person to collect and submit reports on behalf of county residents. As a result, the LDIG was able to design a simplified survey, distribute and collect it regularly, and enter all the reports into AZDW. We noted a jump in reporting rates when this arrangement began in May 2010. Prior to May 2010, no reports came from Mohave County but between May and August 2010 an average of 8 reports each month, containing up to 67 individual impacts, were submitted from Mohave County. The county continues to file regular reports.

Challenges of online tools. A web-based system, like AZDW, has certain specific requirements to ensure success. The website design must facilitate its use, information on the site should be easily accessible and up to date (Newman et al. 2010), and the site should fit the skill level of the intended user group. AZDW has some weaknesses in all these areas. When the site was reviewed by a group of students at Arizona State
University (we considered them a pool of potential users), they provided detailed critiques of the site structure and function. They raised concerns about site design, available information, the search function, and the inclusion of out-of-date information. Their assessments concluded that there was little on the site to entice new users to explore or participate in drought impacts reporting through AZDW.

Diduck and Sinclair (2002) note that participants in their research cited inaccessibility of information as a barrier to participation. In the case of AZDW, participants expected more information to be available on the website and, when the available information did not meet their needs or interests, they tended to drift away from participation. One evaluation participant explained, “[T]here doesn't seem to be enough information to catch peoples' eyes and have them come back to the website." This, of course, presents a paradox for AZDW administrators: people want more information fed back to them, but not enough impact reporters are contributing information to make the feedback worthwhile.

A final potential barrier is the intersection of the use of an online system with participants' skill level. We found that, while few people noted problems with the website, several impact observers and one AZDW developer questioned whether the intended users, in fact, had the skills necessary to use the technology on their own. One study participant felt that members of his LDIG were "polite" in the meetings when the online format was discussed and did not raise concerns but were not necessarily able to use the site comfortably.

Complexities of drought monitoring. Overlying all the issues of public participation are the inherent complexities of monitoring drought. We saw evidence of this when participants indicated that their perception of drought influenced their willingness to file reports in AZDW. An additional area of confusion lies in the unique role qualitative drought impacts reports play in monitoring. AZDW developers had a very clear vision of how data collected by AZDW would be different but complementary to quantitative drought data. The developers expressed a desire to link the quantitative measures of drought to what is observed and experienced "on the ground" by those most impacted:

[W] get lots of numbers and we don't really know what they mean. One year you can have a 4 inch deficit of precipitation and have no problem and another year you can have a 4 inch deficit and have 
lots of problems...[I]f we could connect those numbers with impacts...we could say to people "when you get a 4 inch deficit, that's when you're likely to see your crops dying..."

In contrast, participants in our evaluation were not clear about the differences between quantitative and qualitative monitoring or about the relative importance of both types of monitoring information. We asked participants why they thought it was important to monitor drought impacts in Arizona, in an attempt to differentiate between hydroclimatic monitoring, such as rain gauges, and qualitative monitoring. Although their answers demonstrated a deep understanding of how drought monitoring in general can benefit state residents by raising awareness of water issues and understanding long-term climate trends, none of the respondents articulated a difference between quantitative data and qualitative data. One person made the distinction in a later question about the goals of AZDW by hypothesizing that AZDW would help researchers "corroborate data with ground observations." This finding echoes Hayes et al.'s (2011, p. 487) observation that "there appears to be a fundamental lack of knowledge or understanding about 1) the importance of monitoring impacts, 2) the usefulness of impact information, and 3) the type of information that is worthwhile to collect."

DISCUSSION AND RECOMMENDATIONS.

Some of the challenges we have identified, such as website design, are specific to AZDW. Some speak to the challenges of engaging volunteers in long-term monitoring efforts. Some reflect the inherent complexity of monitoring drought. However, all of these observations can provide guideposts for development of future drought monitoring systems.

The Arizona drought preparedness plan, through the vehicle of the LDIGs and by extension AZDW, is based on volunteer reporters. While this distributed model of monitoring promises to collect drought impacts from a broad cross section of the state, there are some inherent challenges in relying on volunteers to provide the detailed, consistent information policy makers need. Public participants need to see a clear link between their actions (contributing observations) and an outcome (how those observations are used). This link is not clear to the intended users of AZDW. Efforts should be made to demonstrate to drought impacts reporters how and when their work is being used in decision making to ensure that participants recognize their agency in the decisionmaking process.
Our case study also revealed a gulf between developers' and stakeholders' understanding of the role of qualitative drought impact observations in a drought monitoring system. Despite numerous training and development sessions with the primary AZDW users, stakeholders were unsure about the difference between qualitative impacts monitoring and more conventional qualitative hydroclimatic monitoring. This confusion might also be alleviated with improved feedback to volunteers. If they regularly saw examples of impact reports and how those were being linked with hydroclimatic data they might better understand both the difference between and the role of each type of monitoring data.

The observers' time commitment should be considered by monitoring program developers. Although LDIG members had volunteered to participate, they often found that regular impacts reporting was one commitment too many. Without a direct incentive, such as seeing how their efforts contribute to decision making, volunteers tend to disengage from public processes. The commitment may constrain qualitative data collection more than quantitative participatory processes, like collecting rain gauge data, because providing written descriptions requires more time. The detailed nature of the AZDW survey, which was intended to capture the complexity of drought impacts, may have hindered reporting instead.

Funding for drought impacts monitoring appears to alleviate some of these issues, however. In one county, a person was paid to collect and submit impacts reports, and responses increased and have stayed consistent over time.

The nature of drought also appears to hinder participation in impacts monitoring. We found that participants were unlikely to report when they did not perceive drought impacts. Because drought means different things to different people, this tendency to disengage from reporting when not directly affected by drought impacts has led to spotty and inconsistent reports that do not provide information on stable or improving conditions.

Many of the challenges that arose in attracting and retaining volunteer impacts reporters could be avoided by having a formal, institutionalized, and supported data collection effort centered on an existing agency or agencies with professional field personnel. Professional observers in Arizona canand in many cases already-collect drought impact data as part of their regular duties. They are trained observers who can report on unusual as well as normal conditions in a consistent manner, providing decision makers with the data required to understand 
conditions and adjust policy accordingly. Agency personnel do not require additional incentives, as do volunteers, if the reporting process is integrated into their work. They may also be closer to the drought response decision-making processes of their own agencies, thus making them aware of the role drought monitoring plays in the process. Overcommitment could still be an issue if this task is simply added onto existing duties without consideration of workloads or priorities. However, the issue of disengagement due to drought perception is likely to be eliminated if drought monitoring is institutionalized as status reporting, rather than impacts spot reporting.

At this stage of developing effective qualitative assessment and decision support tools, it would help to have a core group of trained professionals who have a mandate to collect data, can discern the most likely drought-caused impacts, understand the current state of monitoring science, and can actively participate in the process of linking qualitative and quantitative data. Finding agency partners who can support and sustain monitoring efforts should be a top priority in developing drought impacts monitoring programs.

Finally, participation by professional observers seems likely to have an additional long-term benefit. Although some participants reported that, because agency personnel were engaged in drought monitoring efforts, they would not participate themselves, others noted that, if AZDW became a source of high-quality information, they would be more interested in visiting and using the site. Channeling agency-based drought monitoring information through a public reporting system would resolve this apparent conflict. Rather than creating a sense of duplicative efforts, professional observers can help attract volunteers who consider access to such data an incentive to visit the AZDW site and who may be more likely to participate in impacts monitoring if they see examples of how information is being used. Much like the Dream Team's effect on basketball popularity, professional observers can raise the profile of and interest in drought impact reporting.

Maintaining an open, web-based collection system like AZDW that contains observations from agency personnel keeps the door open for public participation, which will likely vary over time given the ebb and flow of drought conditions and the associated interest and capacity to participate. Volunteer impact observations contributed by the public then become a complementary data stream that greatly enhances the consistent core observations made by agency personnel. This then relieves volunteers of the burden of shouldering a critical monitoring data stream but does not shut them out of the process.
While the science of qualitative drought impacts assessments is still in its infancy, it needs to be shepherded along to fulfill its promise of improved characterization of drought. The dream team of professional experts is likely to be the most effective approach. When volunteer stakeholders can enter a more mature process, clear about their role and expectations, and confident that their time and contributions are making a difference to their communities, the Field of Dreams model can become a rich component of drought impact monitoring by providing additional support for the dream team.

ACKNOWLEDGMENTS. Support for Arizona DroughtWatch was provided by the USDA Natural Resources Conservation Service, National Drought Mitigation Center, University of Arizona Water Resources Research Center, University of Arizona Water Sustainability Program, and the Arizona Water Institute. Funding for this research was provided by the National Oceanic and Atmospheric Administration's Climate Program Office through Grant NA07OAR4310382 with the Climate Assessment for the Southwest program at the University of Arizona and the National Drought Mitigation Center. The authors wish to thank Dr. Gregg Garfin, School of Natural Resources and the Environment, University of Arizona; Dr. Stuart Marsh, School of Natural Resources and the Environment, University of Arizona; Susan Craig, Arizona Department of Water Resources; and Aaryn Olsson, Lab of Landscape Ecology and Conservation Biology, Northern Arizona University for their help with this research. The authors wish to thank the editor and three reviewers for their excellent insights and suggested improvement to this article.

\section{REFERENCES}

Arizona Department of Water Resources, cited 2012: Local drought impacts groups. [Available online at www.azwater.gov/AzDWR/StatewidePlanning/ Drought/LDIG.htm.]

Arnstein, S., 1969: A ladder of citizen participation. J. Amer. Inst. Plann., 35, 216-224.

Cheng, A. S., and K. M. Mattor, 2006: Why won't they come? Stakeholder perspectives on collaborative national forest planning by participation level. Environ. Manage., 38, 545-561.

Cooper, C. B., J. Dickinson, T. Phillips, and R. Bonney, 2007: Citizen science as a tool for conservation in residential ecosystems. Ecol. Soc., 12 (2), 11.

Diduck, A., and A. J. Sinclair, 2002: Public involvement in environmental assessment: The case of the nonparticipant. Environ. Manage., 29, 578-588. 
Dietz, T., and P. C. Stern, Eds., 2008: Public Participation in Environmental Assessment and Decision Making. National Academies Press, 301 pp.

Governor's Drought Task Force, 2004: Arizona drought preparedness plan: Operational drought plan. Arizona Department of Water Resources Rep., 107 pp.

Hayes, M. J., O. V. Wilhelmi, and C. L. Knutson, 2004: Reducing drought risk: Bridging theory and practice. Nat. Hazards Rev., 5, 106-113.

—, M. Svoboda, N. Wall, and M. Widhalm, 2011: The Lincoln declaration on drought indices: Universal meteorological drought index recommended. Bull. Amer. Meteor. Soc., 92, 485-488.

Heim, R. R., 2002: A review of twentieth-century drought indices used in the United States. Bull. Amer. Meteor. Soc., 83, 1149-1165.

Keyantash, J., and J. A. Dracup, 2002: The Quantification of Drought: An Evaluation of Drought Indices. Bull. Amer. Meteor. Soc., 83, 1167-1180.

Lemos, M. C., and B. J. Morehouse, 2005: The co-production of science and policy in integrated climate assessments. Glob. Environ. Change, 15, 57-68.

McKinnon, S., 2006: Arizona ranchers, farmers dig in against drought. The Arizona Republic, 27 November.

Newman, G., D. Zimmerman, A. Crall, M. Laituri, J. Graham, and L. Stapel, 2010: User-friendly web mapping: Lessons from a citizen science website. Int. J. Geogr. Inf. Sci., 24, 1851-1869.

Olson, M., 1965: The Logic of Collective Action: Public Goals and the Theory of Groups. Harvard University Press, $176 \mathrm{pp}$.

Pulwarty, R. S., C. Simpson, and C. R. Nierenberg, 2009: The Regional Integrated Sciences and Assessments (RISA) program: Crafting effective assessments for the long haul. Integrated Regional Assessment of Global Climate Change, C. G. Knight and J. Jager, Eds., Cambridge University Press, 367-393.

PytlikZillig, L. M., and A. J. Tomkins, 2011: Public engagement for informing science and technology policy: What do we know, what do we need to know, and how will we get there? Rev. Policy Res., 28, 197-217.

Quiring, S. M., 2009: Developing objective operational definitions for monitoring drought. J. Appl. Meteor. Climatol., 48, 1217-1229.

Redmond, K. T., 2002: The depiction of drought: A commentary. Bull. Amer. Meteor. Soc., 83, 1143-1147.

Robine, J., 2011: Spatial patterns of drought triggers and indicators. M.S. thesis, University of Nebraska at Lincoln Environmental Studies Program, 24 pp.

Talwar, S., A. Wiek, and J. Robinson, 2011: User engagement in sustainability research. Sci. Public Policy, 38, 379-390.

Wagner, D., 2007: Arizona drought: Trees, animals stressed. USA Today, 8 June 2007.

Western Governors Association, 2004: Creating a drought early warning system for the 21st century. Western Governors Association Rep., 14 pp.

Wilhite, D. A., M. J. Hayes, C. Knutson, and K. H. Smith, 2000: Planning for drought: Moving from crisis to risk management. J. Amer. Water Resour. Assoc., 36, 697-710.

—, M. D. Svoboda, and M. J. Hayes, 2007: Understanding the complex impacts of drought: A key to enhancing drought mitigation and preparedness. Water Resour. Manage., 21, 763-774.

World Meteorological Organization, 2006: Drought monitoring and early warning: Concepts, progress, and future challenges. WMO Rep. 1006, 26 pp.

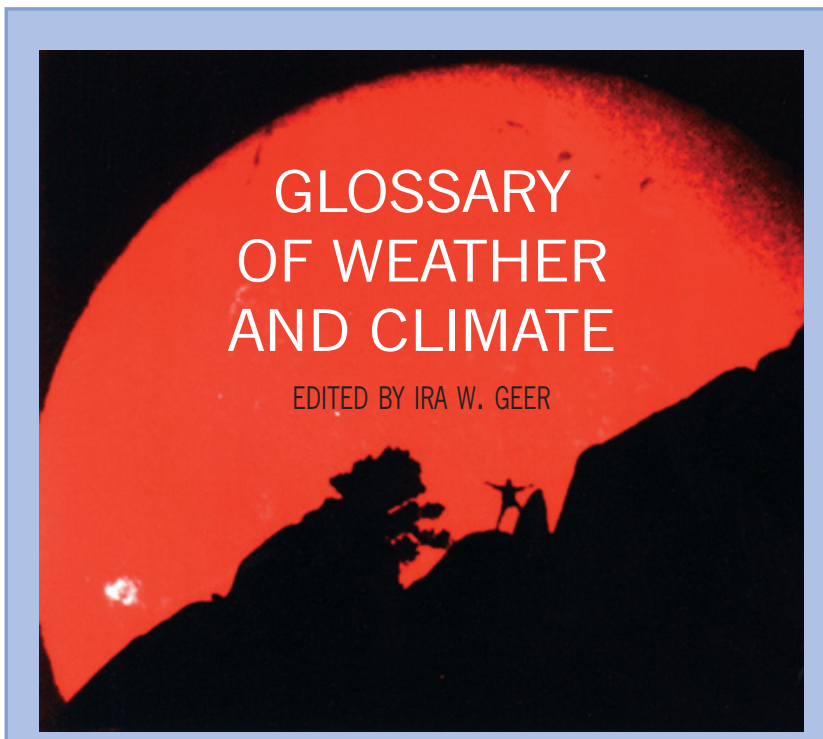

Educators, students, and weather enthusiasts! A glossary of over $\mathbf{3 0 0 0}$ terms on weather and climate designed specifically for a general audience! Produced under the Project ATMOSPHERE initiative, the development of The Glossary of Weather and Climate was inspired by increasing contemporary interest in the atmosphere and global change. The objective of the glossary is to provide a readily understandable, up-to-date reference for terms that are frequently used in discussions or descriptions of meteorological and climatological phenomena. In addition, the glossary includes definitions of related oceanic and hydrologic terms.

(01996 American Meteorological Society. Available in both hardcover and softcover, B\&W, 272 pages, $\$ 26.95$ list/ $\$ 21.00$ member (softcover); \$34.95 (hardcover) plus shipping and handling. Order online at www.ametsoc. org/amsbookstore. Please send prepaid orders to Order Department, American Meteorological Society, 45 Beacon St., Boston, MA 02108-3693. 


\section{Science at Your Fingertips}

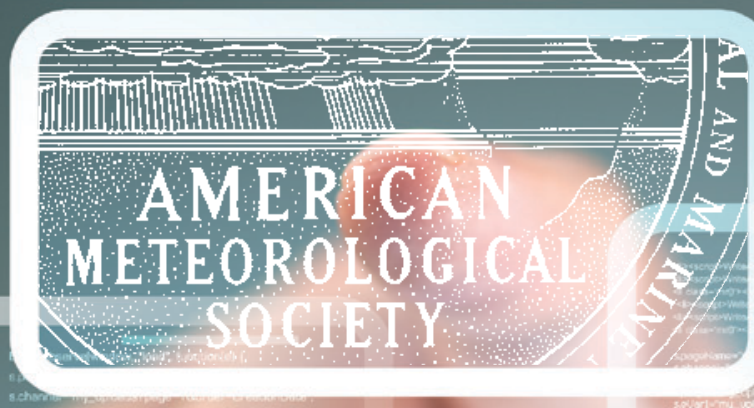

\section{AMS Journals are}

now optimized for viewing on your mobile device.

Access journal articles, monograph titles, and BAMS content using your iOS, Android, or Blackberry phone, or tablet.

Features include:

- Saving articles for offline reading

- Sharing of article links via email and social networks

- Searching across journals, authors, and keywords

And much more...

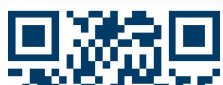

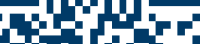

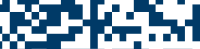

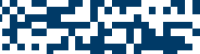

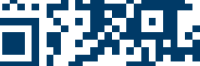

Scan code to connect to journals.ametsoc.org 